\title{
Sensitivity to change of the EORTC quality of life module measuring cancer related fatigue (EORTC QIQ-Fa12): results from the international psychometric validation
}

Running title:

\section{Sensitivity to change of the cancer related fatigue module (EORTC QLQ-FA12)}

Joachim Weis $\mathrm{PhD}^{1}$, Markus A. Wirtz PhD², Krzysztof A. Tomaszewski MD², Eva Hammerlid MD4, Juan Ignacio Arraras $\mathrm{PhD}^{5}$, Thierry Conroy $\mathrm{MD}^{6}$, Anne Lanceley $\mathrm{PhD}^{7}$, Heike Schmidt $\mathrm{MD}^{8}$, Susanne Singer $\mathrm{PhD}^{9}$, Monica Pinto $\mathrm{PhD}^{10}$, Mohamed Alm El-Din MD ${ }^{11}$, Inge Compter MD ${ }^{12}$, Bernhard Holzner $\mathrm{PhD}^{13}$, Dirk Hofmeister $\mathrm{PhD}^{14}$, Wei-Chu Chie MD ${ }^{15}$, Amelie Harle PhD ${ }^{16}$, Hans-Henning Flechtner MD ${ }^{17}$, Andrew Bottomley $\mathrm{PhD}^{18}$

On Behalf of the EORTC Quality of Life Group

$1 \quad$ University Clinic Center Freiburg, Comprehensive Cancer Center, Germany

2 Department of Research Methods, University of Education, Freiburg, Germany

3 Department of Gerontology, Geriatrics and Social Work, Faculty of Education, Ignatianum Academy, Krakow, Poland

$4 \quad$ Department of Otolaryngology Head and Neck Surgery, Sahlgrenska University Hospital, Gothenburg University, Gothenburg, Sweden

$5 \quad$ Oncology departments. Complejo Hospitalario de Navarra. Pamplona. Spain

$6 \quad$ Department of Medical Oncology, Lorraine Cancer Institute, Institut de cancérologie de Lorraine and Université de Lorraine, Nancy, France

$7 \quad$ Institute for Women's Health, University College London, London, UK

8 Institute of Health and Nursing Sciences, Medical Faculty, Martin Luther University Halle-Wittenberg, Germany

$9 \quad$ Division of Epidemiology and Health Services Research, Institute of Medical Biostatistics, Epidemiology and Informatics, University Medical Centre Mainz, Germany

10 Department of Supportive Care, Rehabilitation Medicine Unit, Istituto Nazionale Tumori - IRCCS "Fondazione G. Pascale", Napoli, Italy.

11 Department of Clinical Oncology, Tanta Faculty of Medicine, Egypt

12 Department of Radiation Oncology (MAASTRO), GROW (School for Oncology \& Developmental Biology), University of Maastricht Medical Center, Maastricht, The Netherlands

13 Department of Psychiatry and Psychotherapy, Medical University of Innsbruck, Austria

14 Department of Medical Psychology and Medical Sociology, University of Leipzig, Germany

15 Department of Family Medicine, National Taiwan University, Taiwan

16 Medical Oncology Department, The Christie NHS Foundation Trust, Manchester UK.

17 Department of Paediatric Psychiatry, University of Magdeburg, Germany

18 Quality of Life Department, EORTC Headquarters, Brussels, Belgium

\section{Acknowledgement}

We thank all collaborators and the patients who helped us develop this module. This study was funded by the European Organisation for Research and Treatment of Cancer Quality of Life Group (EORTC QoL Group) (grant number: v1 04/09). 


\section{Conflict of Interest Statement}

All authors declare that there are no conflicts of interest.

\section{Author Contribution Statement:}

Study concepts: Joachim Weis, Andrew Bottomley, Henning Flechtner

Study design: Joachim Weis, Andrew Bottomley, Susanne Singer, Hennings Flechtner

Data acquisition: $\quad$ Krzysztof A. Tomaszewski, Eva Hammerlid, Juan Ingacio Arraras, Thierry

Conroy, Anne Lanceley, Heike Schmidt, Monica Pinto, Mohamed Alm El-Din, Inge Compter, Bernhard Holzner, Dirk Hofheister, Wei-Chu Chie, Amelie Harle

Quality control of data and algorithms: Joachim Weis, Markus Wirtz

Data analysis and interpretation: Joachim Weis, Markus Wirtz

Statistical analysis: Markus Wirtz

Manuscript preparation: Joachim Weis, Markus Wirtz

Manuscript editing: Joachim Weis, Markus Wirtz, Andrew Bottomley, Susanne Singer, Krzysztof

A. Tomaszewski, Eva Hammerlid, Juan Ingacio Arraras, Thierry Conroy, Anne Lanceley, Heike Schmidt, Monica Pinto, Mohamed Alm El-Din, Inge Compter, Bernhard Holzner, Dirk Hofheister, Wei-Chu Chie, Amelie Harle Manuscript review: Joachim Weis, Markus Wirtz, Andrew Bottomley, Susanne Singer, Krzysztof A. Tomaszewski, Eva Hammerlid, Juan Ingacio Arraras, Thierry Conroy, Anne Lanceley, Heike Schmidt, Monica Pinto, Mohamed Alm El-Din, Inge Compter, Bernhard Holzner, Dirk Hofheister, Wei-Chu Chie, Amelie Harle 


\section{Abstract}

Objective: The European Organisation for Research and Treatment of Cancer Quality of Life Group (EORTC QLG) has developed a multidimensional instrument measuring cancer related fatigue, the EORTC QLQFA12. The analysis of sensitivity to change is an essential part of psychometric validation. With this study, we investigated the EORTC QLQ-FA12's sensitivity to change.

Methods: The methodology follows the EORTC guidelines of EORTC QLG for phase IV validation of modules. We included cancer patients undergoing curative and palliative treatment at $\mathrm{t} 1$ and followed them up prospectively over the course of their treatment (t2) and four weeks after completion of treatment ( $\mathrm{t} 3$ ). Data were collected prospectively at 17 sites in eleven countries. Sensitivity to change was investigated using analysis of variance (ANOVA).

Results: A total sample of 533 patients were enrolled with various tumour types, different stages of cancer, and receiving either curative treatment $(n=311)$ or palliative treatment $(n=222)$. Over time all fatigue scores were significantly higher in the palliative treatment group compared with the curative group $(p<$ .001). Physical fatigue increased with medium effect size over the course of treatment in the curative group $[\mathrm{SRM}(\mathrm{t} 1, \mathrm{t} 2)=0.44]$. After treatment physical $[\mathrm{SRM}(\mathrm{t} 2, \mathrm{t} 3)=0.39]$, emotional $[\mathrm{SRM}(\mathrm{t} 2, \mathrm{t} 3)=0.28]$ and cognitive fatigue $[\operatorname{SRM}(\mathrm{t} 2, \mathrm{t} 3)=0.22]$ declined significantly in the curative group. In the palliative group emotional $[\operatorname{SRM}(\mathrm{t} 2, \mathrm{t} 3)=0.18]$ as well as cognitive $[\operatorname{SRM}(\mathrm{t} 2, \mathrm{t} 3)=0.26]$ fatigue increased significantly.

Conclusions: The EORTC-QLQ-FA12 proved to identify clinically significant changes in fatigue in the course of curative and palliative cancer treatment.

\section{Keywords}

Cancer related fatigue; international field validation; sensitivity to change; quality of life; module development; EORTC quality of life group 


\section{Background}

Fatigue is one of the most distressing symptoms for cancer patients affecting their quality of life (QoL) in all phases of treatment and stages of the disease. Cancer related fatigue $(\mathrm{CrF})$ is defined as a distressing, persistent subjective sense of physical, emotional and cognitive tiredness or exhaustion related to cancer or cancer treatment that is not proportional to recent activities and interferes with usual functioning. ${ }^{1}$ The degree, duration and frequency of $\mathrm{CrF}$ may vary over time. ${ }^{2,3}$ Prevalence rates of $\mathrm{CrF}$ range from $59 \%$ $100 \% .^{4-6}$ Some studies have demonstrated that CrF usually increases during chemotherapy and decreases afterwards but may persist up to one year or longer. ${ }^{7,8}$ Comparing various treatment options some studies have shown that severe $\mathrm{CrF}$ is more prevalent among patients receiving chemotherapy or concurrent chemoradiation compared with patients receiving only radiotherapy. ${ }^{9,10}$ There is some evidence that treatment with opioids, poor performance states and weight loss are the strongest predictors for CrF. ${ }^{11}$ Prevalence of $\mathrm{CrF}$ is higher in patients receiving palliative care. ${ }^{12}$ Previous findings reported that $\mathrm{CrF}$ as a long term sequelae or late effect is estimated to have an average prevalence rate of approximately $30 \%$ for up to 10 years or more. ${ }^{13-15}$ As uncontrolled symptoms like CrF are associated with increased psychological distress, loss of physical functioning, and a decrease in QOL it is essential to assess CrF systematically. ${ }^{16}$ Therefore, a standardized questionnaire measuring $\mathrm{CrF}$ should be able to detect changes in fatigue levels over the trajectory of cancer.

During the last decade, interest and research in CrF has increased considerably. More detailed uni- or multidimensional instruments have been developed to assess CrF. ${ }^{17}$ In guidelines for managing fatigue it is recommended to use cancer-specific fatigue scales instead of generic fatigue scales. ${ }^{1,4}$ Against this background the EORTC-FA13 module was developed following the methodological guidelines of EORTC, which include four phases of development (I. generation of issues, II. construction of items list, III. pretesting, IV. field testing). ${ }^{18}$ The pre-tested module EORTC QLQ-FA13 (phase III) based on a multidimensional concept of fatigue included 13 items (2 global items on interference with daily activities and social sequelae of fatigue and 11 items allocated to a physical, emotional or cognitive domain) (see appendix A) and was designed to measure fatigue in conjunction with the quality of life core questionnaire EORTC QLQ-C30.19 The multidimensional scale structure of EORTC QLQ-FA12 (phase IV module) has 
already been validated 20 and confirmed in further studies. ${ }^{21}$ Analysis of its sensitivity to change is reported here.

\section{Methods}

According to the EORTC Quality of Life Group guidelines for development of new questionnaires, ${ }^{18}$ the analysis of sensitivity to change is an important part of phase IV validation of the module EORTC QLQFA12. This paper analyses the sensitivity to change focusing on two research questions:

1. Which scales of the FA12 are able to detect clinical changes over time? (sensitivity to change)?

2. Does the EORTC QLQ-FA12 allow the identification of clinically relevant differences between the curative and the palliative treatment groups over time (differential treatment responsiveness)?

We hypothesized overall higher fatigue scores for the palliative group compared with the curative group. Further, we expected statistically significant changes over time dependent on the type of treatment group (curative vs. palliative).

The design of our study followed the guidelines of EORTC for the development of modules in phase IV and is described in detail elsewhere. ${ }^{20}$ Here we focus solely on the longitudinal analyses of the changes. Patients were enrolled in two distinct groups and assessed at three time points (t1-t3) as follows:

- group A: Cancer patients with first-line treatment with curative intention

- $\quad$ group B: Cancer patients with second-line treatment with palliative intention

For both groups, $\mathrm{t} 1_{\mathrm{AB}}$ was predefined at \pm 7 days before or at the 1 st day of treatment (adjuvant chemo/radiotherapy). In both groups, $2_{\mathrm{AB}}$ was determined at the end of the $2 \mathrm{nd}$ cycle or at the beginning of the 3rd cycle of chemotherapy, for radiotherapy $2_{A B}$ was at the end of the 4th week of radiotherapy. For the curative group (A) t3A was accomplished at three months (range: 12-15 weeks) after treatment, for the palliative group (В) ТВ at one month (range: 4-6 weeks) after treatment to avoid higher drop-out rates (table 1). Patients were invited to complete the EORTC core questionnaire (EORTC QLQ-C30 version 3.0) and the fatigue module EORTC QLQ-FA12. All patients provided clinical and socio-demographic data (gender, date of birth, country of origin, marital status, education level, employment status). Time since diagnosis, tumour locations, type of treatments, metastases, ECOG Performance Status were obtained from the medical records from each cooperating center. 
Insert table 1 here

The study was carried out as an international multicenter study across 17 centres in 9 European (England, France, Germany, Austria, Poland, the Netherlands, Sweden, Spain, Italy) and 2 Non-European countries (Egypt and Taiwan). We initially calculated a sample of 135 patients per group (total of $n=270$ ) defining a sample size per center between 10 to 20 patients. ${ }^{19}$ Patients were recruited from February 2011 to November 2014. During the recruitment period we had bi-annual meetings to monitor the recruitment process. The study was registered with the German Clinical Trial Studies Registry (DRKS-ID: DRKS00003091). National and local ethics approvals were obtained at the recruiting centers before commencement of the study (ethical approval, study center, Freiburg Germany No. 165/11).

\section{Inclusion and exclusion criteria}

Patients with cancer of all tumour sites were included if they met the following criteria: Patients with histologically confirmed cancer and aged over 18 years, with written informed consent and the ability to understand the language of the questionnaire. Patients with severe psychiatric or cognitive mental conditions potentially hampering compliance with the study protocol and follow-up schedule, and patients undergoing allogeneic haematological stem cell transplantation (HSCT) or neo-adjuvant therapy were excluded. In addition, patients were excluded if they were participating in other QoL-studies that might interfere with this validation study.

\section{Statistical methods}

Data entry, management and statistical evaluation were conducted from the coordination centre in Freiburg, Germany. Data analysis was done using SPSS v21 supported from a biostatistician specialized in psychometric analyses. For each measurement point in time, missing responses were imputed by Expectation-Maximization-Estimates separately. ${ }^{22}$ Missing data diagnostics have been applied to identify potential systematic drop-out of patients over measurement points in time. ${ }^{23}$ As underlying missing data processes could not be modelled sufficiently, only patients taking part in the assessment at all three measurement points were included in the analyses. For dropout analyses we used $\mathrm{Chi}^{2}$ in case of 
categorical data and t-tests for independent groups in case of metric data. To determine reliability over time we used Pearson correlation for each group (group A and B) separately as differences between the two groups are to be expected. Sensitivity to change was analyzed using ANOVA with pairwise comparisons $(\mathrm{t} 1 / \mathrm{t} 2, \mathrm{t} 2 / \mathrm{t} 3, \mathrm{t} 1 / \mathrm{t} 3)$ and standardized response means (SRM). ${ }^{24,25}$ For interpretation of the effect sizes we followed Cohen ${ }^{24}$ (SRM $\leq 0.1$ = small effect; $0.1<S R M<0.5 \geq$ medium effect; $S R M>0.5=$ large effect).

\section{Results}

Due to higher drop-out rates than expected, we increased recruitment and therefore the total sample consisted of $n=533$ patients (at $t 1_{A B}$ ) (group $A n=311$, group $B n=222$ ) (table 2 ). The average age was 61.0 $(S D=13.1)$ years (range from 26-97 years). On average patients in group $B$ were 3.5 years older than patients in group A (62.7 vs. 59.3 years).

Insert table 2 here

Gender distribution was balanced (female $51.6 \%$, male 48.4\%) (t1). As planned, the sample comprised of a wide spectrum of tumour diagnoses with the highest percentages in head and neck cancer (22.9\%), breast cancer (18.9\%), lung cancer (17.3\%) and colorectal cancer (10.5\%).

ECOG status for most patients was 0 (fully active $37.2 \%$ ) and I (38.4\%); only $18.1 \%$ were in stage II, $5.1 \%$ in stage III and $1.2 \%$ in stage IV. In total, the palliative group had a higher ECOG score than the curative group showing a higher degree of functional impairment. In $40.3 \%$ of the patients, distant metastases were prevalent. As expected patients in group B (palliative treatment) showed a higher rate of metastases (83.6\%) compared with the group A (curative treatment) (10.1\%). For treatment, most patients received surgery $(50.8 \%)$, chemotherapy $(63.6 \%)$, radiotherapy $(52.0 \%)$ or hormone therapy $(4.7 \%)$.

All CrF subscale scores were significantly higher for the palliative group (mean physical $=46.00, S D=25.67$; mean $_{\text {emotional }}=36.67, \quad \mathrm{SD}=30.33 ;$ mean $\left._{\text {cognitive }}=16.99, \mathrm{SD}=22.67\right)$ compared with curative group ( $_{\text {mean }}$ physical $=34.67, \mathrm{SD}=27.67 ;$ mean $_{\text {emotional }}=26.00, \mathrm{SD}=27.98$; mean $_{\text {cognitive }}=11.67 \mathrm{SD}=20.00$ ). The dropout rate in the palliative group was higher (38.3\%) than in the curative group (25.4\%) (see also main effects "group" in Table 4). In both groups drop-out was associated with higher ECOG scores (impairment), lung cancer, undergoing surgical treatment, and higher physical fatique, respectively. Whilst in the curative group 
the proportion of patients with metastases decreased (10.1\% to $7.4 \%$ ), the proportion increased (from $83.6 \%$ to $88.0 \%$ ) in the palliative group. In the curative group patients suffering from breast cancer, elderly people and patients taking part in "other" treatments exhibited higher drop-out rates. In the palliative group taking part in hormone treatment was associated with a higher rate of study retention.

For the analysis of sensitivity to change (see table 3 and 4), we used data from all patients who completed the three points of measurement (curative group: $n=232$; palliative group: $n=137$ ). Time between $t 1$ and $t 2$ was on an average of 6.1 weeks for the curative group and 5.6 weeks for the palliative group. Time differences between $\mathrm{t} 1$ and $\mathrm{t} 3$ was on average 20.1 weeks (approx. 5 months) for the curative group and 13.8 weeks (approx. 3.5 months) for the palliative group.

Insert tables 3 and 4 here

Analysing group specific mean differences over time (t1-t3) we found significant changes and differences between the two treatment groups for physical fatigue with an interaction between time and treatment groups $(p<.001)$. In the curative group physical fatigue increased over the course of the treatment $(\mathrm{SRM}(\mathrm{t} 1, \mathrm{t} 2)=0.44)$ and decreased after treatment almost to the baseline level $(\mathrm{SRM}(\mathrm{t} 2, \mathrm{t} 3)=0.39)$. After treatment emotional and cognitive fatigue decreased significantly with a small effect size in the curative group $(\mathrm{SRM}(\mathrm{t} 2, \mathrm{t} 3)=0.28,0.22)$ as well as in the palliative group $(\mathrm{SRM}(\mathrm{t} 2, \mathrm{t} 3)=0.18,0.26)$.

In the curative group highest fatigue values weremeasured in the treatment phase (t2) on all three dimensions. In the palliative group highest fatigue values prevailed at $\mathrm{t} 3$. These differing trends over time tested by the interaction effect of time and group proved to be significant with a small effect size (Partial etasquared $=.018$ to .025 ; see table 4 )

Additionally, table 3 and 4 depict the results for the two global items "Did tiredness interfere with your daily activities (home, leisure activities)" [FA12] and "Did you feel that your tiredness is (was) not understood by the people close to you?" [FA13] to complete the information on the original EORTC QLQ-FA13 items. For item F12 results are similar as for physical fatigue in both groups: values are significantly enhanced at $\mathrm{t} 2$ in the curative group $[\mathrm{SRM}(\mathrm{t} 1, \mathrm{t} 2)=0.32 ; \mathrm{SRM}(\mathrm{t} 1, \mathrm{t} 2)=0.23]$, and values are significantly higher after treatment 
in the palliative group [SRM $(t 2, t 3)=0.19$; interaction of time and group: $p<.001]$. No significant effects were found for item FA13.

Pearson correlations or the subscales (physical, emotional and cognitive fatigue) in table 3 indicate stability in the deviation of patients' fatigue values from the group and time-specific mean values (consistency definition according to McGraw \& Wong, 1996). ${ }^{26}$ This mean-corrected measure indicates that fatigue remained more stable in the palliative group from $t 1$ to $t 2$ (palliative group: $r_{\text {phys }}=.58, r_{e m o t}=.70$, $r_{\text {cogn }}=.71$; curative: $\left.r_{\text {phys }}=.51, r_{\text {emot }}=.52, r_{\text {cogn }}=.56\right)$. From t2 to t3 the picture then shifts to the opposite as the stability of fatigue values in the curative group $\left(r_{\text {phys }}=.60, r_{\text {emot }}=.61, r_{c o g n}=.63\right)$ are higher than in the palliative group $\left(r_{\text {phys }}=.47, r_{\text {emot }}=.56, r_{\operatorname{cog} n}=.55\right)$.

\section{Conclusions}

To complete the psychometric validation of the EORTC fatigue module FA13 we provide data of the validation study analysing the sensitivity to change for the new EORTC QLQ-FA12 module.

We conducted a prospective longitudinal assessment at three points of measurement in two distinct groups of patients treated with curative intention (group A) and palliative intention (group B). We were able to include a large cross-cultural sample of cancer patients with different diagnoses, which guarantees the crosscultural applicability of this module, in line with the EORTC tradition.

In the longitudinal analysis we had acceptable dropout rates for such studies showing a higher loss rate for patients in the palliative group. Dropout was associated in both groups with higher ECOG scores, higher metastatic disease burden, lung cancer and higher scores of physical fatigue; and for the curative group only with age. The analyses of the sensitivity to change detected satisfactory results for patients in curative treatment (group A) compared with patients under palliative treatment (group B). For the group receiving curative treatment only a slight increase of all fatigue scores up to t2 with a medium effect size reflected the direct impact of the treatment with a corresponding decrease up to t3 three months after end of treatment. Further, physical and emotional fatigue have been proven most sensitive to changes explained by the effect of treatment over time with slight differences within the palliative group. In this group overall effect sizes 
were small to medium, which may be explained by the comparatively short period of observation of five or three and a half months. In the curative group, we found small effects in all sub-dimensions of EORTC QLQFA12 for the pairwise comparisons of all three points of measurement (before treatment up to the end of treatment). Our results correspond to the findings from the literature showing overall higher scores for palliative patients. ${ }^{12,27}$ Patients in palliative care are suffering mostly from long lasting fatigue which may not be changed by ongoing treatment. Therefore, larger changes of the fatigue scores over this time period were not to be expected. Overall, we could demonstrate that EORTC QLQ-FA12 is able to detect changes over time in both groups. Furthermore, mean-corrected stability (Pearson correlation) measures indicated satisfactory stabilities for the three dimensions $(r=.47$ to .71$)$. Higher stability estimates were not be expected, because patients take part in various treatments and fatigue is generally a time-variant person characteristics. Higher stability in all three dimensions from t 1 to $t 2$ in the palliative group, and higher stability in all three dimensions from t2 to $\mathrm{t} 3$ in the curative group, suggest different treatment dependent development over time for curative and palliative treated cancer patients.

\section{Study limitations}

Our study had some limitations. First, we could not achieve equal sample sizes for all participating countries, as the patient recruitment proceeded at different rates in the various countries. In addition, according to the broad eligibility criteria we have included a heterogenous sample with various cancer diagnoses which is not representative of the prevalence or incidence rates of the respective cancer diagnoses. As our results are not representative for the various cancer diagnoses there is a need for further studies investigating EORTC QLQ-FA12 in longitudinal clinical trials with specific cancer diagnoses.

Also, the recruitment in the palliative care group (group B) was more difficult than anticipated and drop-out rates for these patients were a bit higher than allowed for in our original design. We were able to compensate losses in statistical power to some extent, by increasing the initial patient numbers. A detailed analysis of the drop-outs allowed us to identify the potential factors which may have caused bias. As drop- out is associated with disease and cancer type related aspects, a consequential bias may have affected the sensitivity to change.

\section{Clinical implications}


In summary, the EORTC QLQ-FA12 is now available as an internationally validated phase IV module to be used for measuring cancer related fatigue in clinical trials in conjunction with the EORTC QLQ-C30. As fatigue is often underreported by patients EORTC QLQ-FA12 may also be used to assess fatigue symptoms in routine clinical practice to identify fatigue as an indicator of unmet care needs. The module is currently available in the following languages: Arabic, Chinese Mandarin (China), Chinese Mandarin (Taiwan), Dutch, English, French (Europe), German, Italian, Japanese, Norwegian, Polish, Portuguese (Brazil) Spanish (Mexico), Spanish (Spain), Swedish and is available from the EORTC Quality of Life Department. 


\section{References:}

1. NCCN (National Comprehensive Cancer Network). Clinical practice guidelines in oncology: cancer related fatigue. Published February, 2018. Accessed 29th January, 2019.

2. Henry DH, Viswanathan HN, Elkin EP, et al. Symptoms and treatment burden associated with cancer treatment: results from a cross-sectional survey in the U.S. Support Care Cancer. 2008;16:791-801.

3. Wagner LI, Cella D. Fatigue and cancer: causes, prevalence and treatment approaches. Br J Cancer. 2004;91:822-828.

4. Bower JE, Bak K, Berger A, et al. Screening, assessment, and management of fatigue in adult survivors of cancer: An American Society of Clinical Oncology Clinical Practice Guideline Adaptation. JCO, 2014;32:1840-1850. doi:10.1200/JCO.2013.53.4495.

5. Servaes P, Gielissen MF, Verhagen S, Bleijenberg G. The course of severe fatigue in disease-free breast cancer patients: a longitudinal study. Psycho-Oncology. 2007;16(9):787-795.

6. Arndt V, Stegmaier C, Ziegler H, Brenner H. A population-based study of the impact of specific Symptoms on Quality of Life in Woman with Breast Cancer 1 Year after Diagnosis. Cancer. 2006;107(10):2496-2503.

7. Fabi A, Falcicchio C, Giannarelli D, et al. The course of cancer related fatigue up to ten years in early breast cancer patients: What impact in clinical practice? The Breast. 2017;34:44-52.

8. Williams AL, Heckler CE, Paterson CL, et al. Cancer-related fatigue in breast cancer survivors: A longitudinal analysis compared to matched controls. JCO. 2017;35(15).

doi:10.1200/JCO.2017.35.15_suppl.10045.

9. Karthikeyan G, Jumnani D, Prabhu R, et al. Prevalence of fatigue among cancer patients receiving various anticancer therapies and its impact on quality of life: a cross-sectional study. Indian J Palliat Care. 2012;18(3):165-175.

10. Donovan KA, Jacobsen PB, Andrykowski MA, et al. Course of fatigue in women receiving chemotherapy and/or radiotherapy for early stage breast cancer. J Pain Symptom Manage. 2004;28(4):373-80. 
11. Wang XS, Zhao F, Fisch MJ, et al. Prevalence and characteristics of moderate-to-severe fatigue: a multicenter study in cancer patients and survivors. Cancer. 2014;120(3):425-432.doi:10.1002/cncr.28434 .

12. Teunissen SC, Wesker W, Kruitwagen C, et al. Symptom prevalence in patients with incurable cancer: a systematic review. J Pain Symptom Manage. 2007;34(1):94-104.

13. Bower JE, Ganz PA, Desmond KA, et al. Fatigue in long-term breast carcinoma survivors. A longitudinal investigation. Cancer. 2006;106(4):751-758.

14. Junghaenel DU, Cohen J, Schneider S, et al. Identification of distinct fatigue trajectories in patients with breast cancer undergoing adjuvant chemotherapy. Support Cancer Care. 2015;23(9):2579-2587.

15. Goldstein D, Bennett BK, Webber K, et al. Cancer-related fatigue in women with breast cancer: outcomes of a 5-year prospective cohort study. JCO. 2012;30:1805-1812.

16. Cooley M, Short TH, Moriarty HJ. Symptom prevalence, distress and change over time in adults receiving treatment for lung cancer. Psycho-Oncology. 2003;12:694-708. doi:10.1002/pon.694.

17. Minton O, Stone P. A systematic review of the scales used for the measurement of cancer-related fatigue (CRF). Annals of Oncology. 2009;20:17-25.

18. Johnson CD, Aaronson A, Blazeby JM, et al. eds. Guidelines for Developing Questionnaire Modules. $4^{\text {th }}$ ed. Brussels: EORTC; 2011.

https://www.eortc.org/app/uploads/sites/2/2018/02/guidelines_for_developing_questionnaire-_final.pdf. Acessed January 28, 2019.

9. Weis J, Arraras JI, Conroy T, et al. Development of an EORTC quality of life phase III module measuring cancer-related fatigue (EORTC QLQ-FA13). Psycho-Oncology.2013;22.1002-1007. doi: 10.1002/pon.3092.

20. Weis J, Tomaszewski KA, Hammerlid E, et al. International psychometric validation of an EORTC quality of life module measuring cancer related fatigue (EORTC QLQ-FA12). J National Cancer Institute. 2017;109(5).doi 10.1093/jnci/djw273. 
21. Kecke S, Ernst J, Einenkel J, et al. Psychometric properties of the fatigue questionnaire EORTC QLQFA12 in a sample of female cancer patients. J Pain Symptom Manage. 2017;54(6):922-928. doi:10.1016/j.jpainsymman.2017.08.007.

22. Graham JW. Missing Data. Analysis and Design. New York: Springer; 2012.

23. Tabachnik BG, Fidell LS. Using multivariate statistics. London: Harper \& Row; 2001.

24. Hair JF. Multivariate data analysis. $7^{\text {th }}$ ed. Upper Saddle River, NJ: Prentice Hall; 2010.

25. Cohen J. A power primer. Psychological Bulletin. 1992;112(1):155-159. doi:10.1037/00332909.112.1.155. PMID 19565683.

26. McGraw KO; Wong SP. Forming inferences about some intraclass correlation coefficients. Psychological Methods. 1996;1(1):30-46. doi:10.1037/1082-989X.1.1.30.

27. Radbruch L, Strasser F, Elsner F, et al. Fatigue in palliative care patients - an EAPC approach. Palliat Med. 2008;22:13-32. 
Table 1 Points of measurements and drop-out rates

\begin{tabular}{|c|c|c|}
\hline $\begin{array}{l}\text { Points of } \\
\text { measurement }\end{array}$ & $\begin{array}{l}\text { Group A } \\
\text { (curative) }\end{array}$ & $\begin{array}{l}\text { Group B } \\
\text { (palliative) }\end{array}$ \\
\hline $\mathrm{t} 1$ & $\begin{array}{l}\mathrm{T} 1_{\mathrm{A}} \\
\pm 7 \text { days before or at the } 1 \text { st day of } \\
\text { treatment (adjuvant chemo- } \\
\text { /radiotherapy) } \\
\mathrm{n}=311\end{array}$ & $\begin{array}{l}\mathrm{T} 1_{\mathrm{B}} \\
\pm 7 \text { days before or at the } 1 \text { st day of } \\
\text { treatment (adjuvant chemo- } \\
\text { /radiotherapy) } \\
\mathrm{n}=222\end{array}$ \\
\hline $\mathrm{t} 2$ & $\begin{array}{l}\mathrm{T} 2 \mathrm{~A} \\
\text { ChTh: at the end of } 2 \mathrm{nd} \text { cycle or at } \\
\text { the beginning of the } 3 \text { rd cycle; } \\
\text { Radioth.: at the end of the } 4 \text { th week } \\
\text { of radiotherapy } \\
\mathrm{n}=279 \text { (drop out: } 10.3 \% \text { ) }\end{array}$ & $\begin{array}{l}\mathrm{T} 2 \mathrm{~B} \\
\text { ChTh: at the end of } 2 \mathrm{nd} \text { cycle or at the } \\
\text { beginning of the } 3 \text { rd cycle; } \\
\text { Radioth.: at the end of the } 4 \text { th week of } \\
\text { radiotherapy } \\
\mathrm{n}=181 \text { (drop out: } 18.5 \% \text { ) }\end{array}$ \\
\hline $\mathrm{t} 3$ & $\begin{array}{l}\mathrm{T} 3_{\mathrm{A}} \\
\text { at three months (range: } 12-15 \text { weeks) } \\
\text { after treatment } \\
\mathrm{n}=232 \text { (drop-out: } 25.4 \%)\end{array}$ & $\begin{array}{l}\text { Т3 } \\
\text { at one month (range: } 4-6 \text { weeks) after } \\
\text { treatment. } \\
\mathrm{n}=137 \text { (drop-out: } 38.3 \% \text { ) }\end{array}$ \\
\hline
\end{tabular}


Table 2 Sociodemographic and medical data (drop-out analysis)

\begin{tabular}{|c|c|c|c|c|c|c|c|c|c|}
\hline & \multicolumn{3}{|c|}{ Total Sample } & \multicolumn{3}{|c|}{ Group A: Curative treatment } & \multicolumn{3}{|c|}{ Group B: Palliative Treatment } \\
\hline & $\begin{array}{c}\mathbf{t 1} \\
\mathrm{n}=533 \\
(100 \%)\end{array}$ & $\begin{array}{c}\text { complete } \\
\mathrm{n}=369 \\
(67.4 \%)\end{array}$ & $\begin{array}{l}\text { drop-out vs. } \\
\text { complete }\end{array}$ & $\begin{array}{c}\mathbf{t 1} \\
\mathrm{n}=311 \\
(58.3 \%)\end{array}$ & $\begin{array}{c}\text { complete } \\
n=232 \\
(43.5 \%)\end{array}$ & $\begin{array}{c}\text { drop-out vs. } \\
\text { complete }\end{array}$ & $\begin{array}{c}\mathbf{t 1} \\
\mathrm{n}=222 \\
(41.7 \%)\end{array}$ & $\begin{array}{c}\text { complete } \\
n=137 \\
(25.7 \%)\end{array}$ & $\begin{array}{l}\text { drop-out vs. } \\
\text { complete }\end{array}$ \\
\hline Age Mean (SD) & $61.0(13.1)$ & $60.4(13.4)$ & \multirow{2}{*}{$\begin{array}{c}\mathrm{t}_{\mathrm{df}=331}= \\
2.1^{*}\end{array}$} & $59.8(13.9)$ & $58.7(14.2)$ & \multirow[t]{2}{*}{$\mathrm{t}_{\mathrm{df}=309}=2.44^{*}$} & $63.1(11.4)$ & $63.3(11.6)$ & \multirow[t]{2}{*}{$\mathrm{t}_{\mathrm{df}=220}=0.4^{\mathrm{n} .}$} \\
\hline Range & $26-98$ & $26-98$ & & $26-88$ & $26-88$ & & $31-98$ & $31-98$ & \\
\hline Sex & & & $\chi_{\mathrm{df}=1}^{2}$ & & & $\chi_{\mathrm{df}=1}^{2}$ & & & $\chi_{\mathrm{df}=1}^{2}$ \\
\hline Female & $275(51.6 \%)$ & $189(50.9 \%)$ & \multirow{2}{*}{$0.2^{\text {n.s. }}$} & $157(50.5 \%)$ & $119(51.3 \%)$ & \multirow{2}{*}{$0.2^{\text {n.s. }}$} & $118(53.2 \%)$ & $69(50.4 \%)$ & \multirow{2}{*}{$1.2^{\text {n.s. }}$} \\
\hline Male & $258(48.4 \%)$ & $181(49.1 \%)$ & & $154(49.5 \%)$ & $113(48.7 \%)$ & & $104(46.8 \%)$ & $68(49.6 \%)$ & \\
\hline ECOG Score & $\begin{array}{l}(\mathrm{N}=513 ; \\
96.3 \%)\end{array}$ & $\begin{array}{l}(\mathrm{N}=354 ; \\
96.0 \%)\end{array}$ & $\chi_{\mathrm{df}=4}^{2}$ & $\begin{array}{l}(\mathrm{N}=298 ; \\
95.8 \%)\end{array}$ & $\begin{array}{l}(\mathrm{N}=223 ; \\
96.1 \%)\end{array}$ & $\chi_{\mathrm{df}=4}^{2}$ & $\begin{array}{l}(\mathrm{N}=215 ; \\
96.8 \%)\end{array}$ & $\begin{array}{l}(\mathrm{N}=131 ; \\
95.6 \%)\end{array}$ & $\chi_{\mathrm{df}=4}^{2}$ \\
\hline 0 Fully active & $191(37.2 \%)$ & $151(42.7 \%)$ & \multirow{5}{*}{$32.0^{* * *}$} & $151(48.6 \%)$ & $118(52.9 \%)$ & \multirow{5}{*}{$12.9^{*}$} & $40(18.0 \%)$ & $33(25.2 \%)$ & \multirow{5}{*}{$19.3^{* *}$} \\
\hline I Restricted & $197(38.4 \%)$ & $132(37.3 \%)$ & & $103(33.1 \%)$ & $80(36.9 \%)$ & & $94(42.3 \%)$ & $52(39.7 \%)$ & \\
\hline II Self care & $93(18.1 \%)$ & $61(17.2 \%)$ & & $35(11.3 \%)$ & $22(9.9 \%)$ & & $58(26.1 \%)$ & $39(29.8 \%)$ & \\
\hline III Limited self care & $26(5.1 \%)$ & $9(2.5 \%)$ & & $\begin{array}{ll}8 & (2.6 \%) \\
\end{array}$ & $3(1.3 \%)$ & & $18(8.1 \%)$ & $6(4.6 \%)$ & \\
\hline $\begin{array}{l}\text { IV Completely } \\
\text { disabled }\end{array}$ & $6(1.2 \%)$ & $1(1.2 \%)$ & & $1(0.3 \%)$ & $0(0.0 \%)$ & & $5(2.3 \%)$ & $1(.8 \%)$ & \\
\hline Metastases & $\begin{array}{l}(\mathrm{N}=519 \\
97.4 \%)\end{array}$ & $\begin{array}{l}(\mathrm{N}=363 ; \\
98.4 \%)\end{array}$ & $\chi_{\mathrm{df}=1}^{2}$ & $\begin{array}{c}(\mathrm{N}=306 \\
98.4 \%)\end{array}$ & $\begin{array}{l}(\mathrm{N}=230 \\
99.1 \%)\end{array}$ & $\chi_{\mathrm{df}=1}^{2}$ & & & $\chi_{\mathrm{df}=1}^{2}$ \\
\hline No & $310(59.7 \%)$ & $229(63.1 \%)$ & \multirow{2}{*}{$5.7^{*}$} & $275(89.9 \%)$ & $213(92.6 \%)$ & \multirow{2}{*}{$7.6^{* *}$} & $35(16.4 \%)$ & $16(12.0 \%)$ & \multirow{2}{*}{$5.0^{*}$} \\
\hline Yes & $209(40.3 \%)$ & $134(36.9 \%)$ & & $31(10.1 \%)$ & $17(7.4 \%)$ & & $178(83.6 \%)$ & $117(88.0 \%)$ & \\
\hline Location of tumour & & & $\chi_{\mathrm{df}=1}^{2}$ & & & $\chi_{\mathrm{df}=1}^{2}$ & & & $\chi_{\mathrm{df}=1}^{2}$ \\
\hline Breast & $101(18.9 \%)$ & $80(21.7 \%)$ & $5.8^{*}$ & $60(19.3 \%)$ & $53(22.8 \%)$ & $7.4^{* *}$ & $41(18.5 \%)$ & $27(19.7 \%)$ & $0.4^{\text {n.s. }}$ \\
\hline Head/Neck & $122(22.9 \%)$ & $86(23.3 \%)$ & $0.1^{\text {n.s. }}$ & $90(28.9 \%)$ & $68(29.3 \%)$ & $0.6^{\text {n.s. }}$ & $32(14.4 \%)$ & $18(13.1 \%)$ & $0.5^{\text {n.s. }}$ \\
\hline Lung & $92(17.3 \%)$ & $43(11.7 \%)$ & $26.4^{* * * *}$ & $42(13.5 \%)$ & $24(10.3 \%)$ & $7.8^{* *}$ & $50(22.5 \%)$ & $19(13.9 \%)$ & $15.4 * * *$ \\
\hline Colorectal & $56(10.5 \%)$ & $38(10.3 \%)$ & $0.4^{\text {n.s. }}$ & $33(10.6 \%)$ & $21(10.6 \%)$ & $3.3^{\text {n.s. }}$ & $2310.4 \%)$ & $1712.4 \%)$ & $0.9^{\text {n.s. }}$ \\
\hline Prostate & $21(3.9 \%)$ & $19(5.1 \%)$ & $4.6^{*}$ & $16(5.1 \%)$ & $15(6.5 \%)$ & $3.3^{\text {n.s. }}$ & $5(2.3 \%)$ & $4(2.9 \%)$ & $0.7^{\text {n.s. }}$ \\
\hline Gynaecological & $34(6.4 \%)$ & $27(7.3 \%)$ & $1.8^{\text {n.s. }}$ & $18(5.8 \%)$ & $15(6.5 \%)$ & $0.8^{\text {n.s. }}$ & $16(7.2 \%)$ & $12(8.8 \%)$ & $1.3^{\text {n.s. }}$ \\
\hline Haematological & $27(5.1 \%)$ & $22(6.0 \%)$ & $2.0^{\text {n.s. }}$ & $20(6.4 \%)$ & $16(6.9 \%)$ & $0.3^{\text {n.s. }}$ & $7(3.2 \%)$ & $6(4.4 \%)$ & $1.8^{\text {n.s. }}$ \\
\hline Testicular & $4(0.8 \%)$ & $4(1.1 \%)$ & $1.8^{\text {n.s. }}$ & $3(1.0 \%)$ & $3(1.3 \%)$ & $1.0^{\text {n.s. }}$ & $1(0.5 \%)$ & $1(0.7 \%)$ & $0.6^{\text {n.s. }}$ \\
\hline Pancreatic & $13(2.4 \%)$ & $9(2.4 \%)$ & $0.0^{\text {n.s. }}$ & $1(0.3 \%)$ & $0(0.0 \%)$ & $2.9^{\text {n.s. }}$ & $12(5.4 \%)$ & $9(6.6 \%)$ & $0.9^{\text {n.s. }}$ \\
\hline Others & $78(14.6 \%)$ & $51(13.8 \%)$ & $0.6^{\text {n.s. }}$ & $30(9.6 \%)$ & $18(7.8 \%)$ & $3.7^{\text {n.s. }}$ & $48(21.8 \%)$ & $33(24.1 \%)$ & $1.3^{\text {n.s. }}$ \\
\hline $\begin{array}{l}\text { Treatment } \\
\text { (multiple choice) }\end{array}$ & & & $\chi_{\mathrm{df}=1}^{2}$ & & & $\chi_{\mathrm{df}=1}^{2}$ & & & $\chi_{\mathrm{df}=1}^{2}$ \\
\hline Surgery & $271(50.8 \%)$ & $208(56.4 \%)$ & $14.6^{* * * *}$ & $159(51.1 \%)$ & $130(56.0 \%)$ & $8.8^{* *}$ & $112(50.4 \%)$ & $78(56.9 \%)$ & $6.0^{*}$ \\
\hline Chemotherapy & $339(63.6 \%)$ & $229(62.1 \%)$ & $1.2^{\text {n.s. }}$ & $178(57.2 \%)$ & $130(56.0 \%)$ & $0.5^{\text {n.s. }}$ & $161(72.5 \%)$ & $99(72.3 \%)$ & $0.0^{\text {n.s. }}$ \\
\hline Radiotherapy & $277(52.0 \%)$ & $190(51.5 \%)$ & $0.1^{\text {n.s. }}$ & $141(45.3 \%)$ & $101(43.5 \%)$ & $1.2^{\text {n.s. }}$ & $136(61.3 \%)$ & $89(65.0 \%)$ & $2.1^{\text {n.s. }}$ \\
\hline Hormone & $25(4.7 \%)$ & $22(6.0 \%)$ & $4.3^{*}$ & $8(2.6 \%)$ & $6(2.6 \%)$ & $0.0^{\text {n.s. }}$ & $17(7.7 \%)$ & $16(11.7 \%)$ & $8.2^{* * *}$ \\
\hline Others & $33(6.2 \%)$ & $19(5.1 \%)$ & $2.2^{\text {n.s. }}$ & $11(3.5 \%)$ & $5(2.2 \%)$ & $5.1^{*}$ & $22(9.9 \%)$ & $14(10.2 \%)$ & $0.0^{\text {n.s. }}$ \\
\hline $\begin{array}{l}\text { EORTC QLQ- } \\
\text { FA12 (t1) }\end{array}$ & Mean (SD) & Mean (SD) & $\mathbf{t}_{\mathrm{df}=\mathbf{5 2 9}}$ & Mean (SD) & Mean (SD) & $t_{d f=307}$ & Mean (SD) & Mean (SD) & $t_{d f=220}$ \\
\hline Physical & $39.34(27.34)$ & $\begin{array}{c}35.42 \\
(25.42)\end{array}$ & $4.6^{* * *}$ & $34.52(27.73)$ & $\begin{array}{c}31.90 \\
(25.19)\end{array}$ & $3.0^{* *}$ & $46.00(25.73)$ & $42.38(25.38)$ & $2.6^{* *}$ \\
\hline Emotional & $30.33(29.01)$ & $\begin{array}{c}29.22 \\
(28.59)\end{array}$ & $1.4^{\text {n.s. }}$ & $25.75(27.98)$ & $26.05(27.88)$ & $0.6^{\text {n.s. }}$ & $36.59(30.38)$ & $34.79(29.02)$ & $1.2^{\text {n.s. }}$ \\
\hline Cognitive & $13.71(21.38)$ & $\begin{array}{c}12.94 \\
(19.70)\end{array}$ & $1.0^{\mathrm{n} . \mathrm{s}}$ & $11.61(20.55)$ & $11.64(19.64)$ & $0.1^{\text {n.s }}$ & $16.96(22.60)$ & 15.59 (19.78) & $1.0^{\text {n.s. }}$ \\
\hline
\end{tabular}

$*=\mathbf{p}<.05, * *=\mathbf{p}<.01, * * * \mathbf{p}<.001 ;$ n.s.= non significant; 
Table 3 Descriptive statistics for group and time of measurement

\begin{tabular}{|c|c|c|c|c|c|c|c|c|c|c|c|}
\hline \multirow[t]{2}{*}{ Dimension } & \multirow{2}{*}{$\begin{array}{l}\text { Treatment } \\
\text { groups }\end{array}$} & \multirow[b]{2}{*}{$\mathrm{N}$} & \multirow{2}{*}{$\begin{array}{c}\mathbf{t 1} \\
\mathrm{M}(\mathrm{SD})\end{array}$} & \multirow{2}{*}{$\begin{array}{c}\mathbf{t 2} \\
\mathrm{M}(\mathrm{SD})\end{array}$} & \multirow{2}{*}{$\begin{array}{c}\mathbf{t 3} \\
\mathrm{M}(\mathrm{SD})\end{array}$} & \multicolumn{2}{|c|}{ t1,t2 } & \multicolumn{2}{|c|}{$\mathbf{t} 2, \mathrm{t} 3$} & \multicolumn{2}{|c|}{ t3, t1 } \\
\hline & & & & & & $\mathrm{SRM}^{\dagger}$ & $\mathrm{r}^{\dagger}$ & $\underset{\dagger}{\mathrm{SRM}}$ & $\mathrm{r}^{+}$ & $\operatorname{SRM}^{\dagger}$ & $\mathrm{r}^{*}$ \\
\hline Physical Fatigue & $\begin{array}{l}\text { curative } \\
\text { palliative }\end{array}$ & $\begin{array}{l}232 \\
137\end{array}$ & $\begin{array}{l}31.90(25.19) \\
42.38(25.38)\end{array}$ & $\begin{array}{l}42.80(25.55) \\
44.68(24.41)\end{array}$ & $\begin{array}{l}34.07(25.01) \\
47.14(25.62)\end{array}$ & $\begin{array}{c}0.44^{\mathrm{H}} \\
0.10\end{array}$ & $\begin{array}{l}.51 \\
.58\end{array}$ & $\begin{array}{c}0.39^{\mathrm{H}} \\
0.10\end{array}$ & $\begin{array}{l}.60 \\
.47\end{array}$ & $\begin{array}{l}0.09 \\
0.17\end{array}$ & $\begin{array}{l}.48 \\
.37\end{array}$ \\
\hline Emotional Fatigue & $\begin{array}{l}\text { curative } \\
\text { palliative }\end{array}$ & $\begin{array}{l}232 \\
137\end{array}$ & $\begin{array}{l}26.05(27.88) \\
34.79(29.02)\end{array}$ & $\begin{array}{l}26.58(25.25) \\
32.89(27.38)\end{array}$ & $\begin{array}{l}20.33(25.58) \\
37.71(30.53)\end{array}$ & $\begin{array}{l}0.02 \\
0.09\end{array}$ & $\begin{array}{l}.52 \\
.70\end{array}$ & $\begin{array}{l}0.28^{\mathrm{H}} \\
0.18^{\mathrm{H}}\end{array}$ & $\begin{array}{l}.61 \\
.56\end{array}$ & $\begin{array}{c}0.19^{\mathrm{H}} \\
0.09\end{array}$ & $\begin{array}{l}.38 \\
.35\end{array}$ \\
\hline $\begin{array}{l}\text { Cognitive } \\
\text { Fatigue }\end{array}$ & $\begin{array}{l}\text { curative } \\
\text { palliative }\end{array}$ & $\begin{array}{l}232 \\
137\end{array}$ & $\begin{array}{c}11.64(19.64) \\
15.59(19.78)\end{array}$ & $\begin{array}{l}13.56(19.38) \\
14.11(17.26)\end{array}$ & $\begin{array}{l}10.03(18.94) \\
19.22(23.21)\end{array}$ & $\begin{array}{l}0.10 \\
0.11\end{array}$ & $\begin{array}{l}.56 \\
.71\end{array}$ & $\begin{array}{l}0.22^{\mathrm{H}} \\
0.26^{\mathrm{H}}\end{array}$ & $\begin{array}{l}.63 \\
.55\end{array}$ & $\begin{array}{l}0.08 \\
0.15\end{array}$ & $\begin{array}{l}.47 \\
.39\end{array}$ \\
\hline $\begin{array}{l}\text { Interference tiredness } \\
\text { and daily activities }\end{array}$ & $\begin{array}{l}\text { curative } \\
\text { palliative }\end{array}$ & $\begin{array}{l}232 \\
137\end{array}$ & $\begin{array}{l}34.63(32.27) \\
49.15(31.59)\end{array}$ & $\begin{array}{l}45.56(29.72) \\
46.47(28.96)\end{array}$ & $\begin{array}{l}38.53(29.36) \\
52.21(31.35)\end{array}$ & $\begin{array}{c}0.32^{\mathrm{H}} \\
0.15\end{array}$ & $\begin{array}{l}.38 \\
.52\end{array}$ & $\begin{array}{l}0.23^{\mathrm{H}} \\
0.19^{\mathrm{H}}\end{array}$ & $\begin{array}{l}.41 \\
.55\end{array}$ & $\begin{array}{l}0.11 \\
0.09\end{array}$ & $\begin{array}{l}.40 \\
.36\end{array}$ \\
\hline $\begin{array}{l}\text { Tiredness was not } \\
\text { understood by close } \\
\text { people }\end{array}$ & $\begin{array}{l}\text { curative } \\
\text { palliative }\end{array}$ & $\begin{array}{l}232 \\
137\end{array}$ & $\begin{array}{l}10.06(20.21) \\
8.52(19.81)\end{array}$ & $\begin{array}{l}11.69(24.73) \\
10.21(20.44)\end{array}$ & $\begin{array}{l}12.08(23.87) \\
10.95(21.43)\end{array}$ & $\begin{array}{l}0.07 \\
0.10\end{array}$ & $\begin{array}{l}.54 \\
.67\end{array}$ & $\begin{array}{l}0.03 \\
0.03\end{array}$ & $\begin{array}{l}.59 \\
.49\end{array}$ & $\begin{array}{l}0.08 \\
0.11\end{array}$ & $\begin{array}{l}.50 \\
.39\end{array}$ \\
\hline
\end{tabular}

${ }^{\mathrm{H}}$ Significant Helmert contrast (see. Table 4); ${ }^{\dagger}$ Standardized response mean; ${ }^{\dagger}$ Pearson correlation

Table 4 ANOVA analyzing group-specific mean differences over time

\begin{tabular}{|c|c|c|c|c|c|c|c|c|}
\hline \multirow[t]{2}{*}{ Dimension } & \multicolumn{2}{|c|}{ time } & \multicolumn{2}{|c|}{ group } & \multicolumn{2}{|c|}{ time $x$ group } & \multicolumn{2}{|c|}{ Pairwise comparisons } \\
\hline & $\mathrm{F}^{\dagger} / \mathrm{df} / \mathrm{p}$ & $\begin{array}{c}\text { Partial } \\
\text { eta- } \\
\text { squared }\end{array}$ & $\mathrm{F}^{\dagger} / \mathrm{df} / \mathrm{p}$ & $\begin{array}{c}\text { Partial } \\
\text { eta- } \\
\text { squared }\end{array}$ & $\mathrm{F}^{\dagger} / \mathrm{df} / \mathrm{p}$ & $\begin{array}{c}\text { Partial } \\
\text { eta- } \\
\text { square } \\
\text { d }\end{array}$ & $\begin{array}{l}\text { within groups } \\
\text { between time }\end{array}$ & $\begin{array}{l}\text { between groups } \\
\text { with time }\end{array}$ \\
\hline \multirow[t]{2}{*}{ Physical Fatigue } & \multirow{2}{*}{$\begin{array}{c}12.07 * * * \\
1.96,719 \\
<.001\end{array}$} & \multirow{2}{*}{.066} & \multirow{2}{*}{$\begin{array}{c}16.73 * * * \\
1,367 \\
<.001 \\
\end{array}$} & \multirow{2}{*}{.038} & \multirow{2}{*}{$\begin{array}{c}9.50 * * * \\
1.96,719 \\
<.001\end{array}$} & \multirow{2}{*}{.025} & $\begin{array}{c}\mathrm{M}(\mathrm{C}, \mathrm{t} 2)> \\
{[\mathrm{M}(\mathrm{C}, \mathrm{t} 1)=\mathrm{M}(\mathrm{C}, \mathrm{t} 3)]}\end{array}$ & \multirow{2}{*}{$\begin{array}{l}\mathrm{M}(\mathrm{C}, \mathrm{t} 1)<\mathrm{M}(\mathrm{P}, \mathrm{t} 1) \\
\mathrm{M}(\mathrm{C}, \mathrm{t} 3)<\mathrm{M}(\mathrm{P}, \mathrm{t} 3)\end{array}$} \\
\hline & & & & & & & - & \\
\hline \multirow[t]{3}{*}{ Emotional Fatigue } & \multirow{3}{*}{$\begin{array}{c}0.47 \\
1.78,652 \\
.604\end{array}$} & \multirow{3}{*}{.001} & \multirow{3}{*}{$\begin{array}{c}19.98 * * * \\
1,367 \\
<.001\end{array}$} & \multirow{3}{*}{.052} & \multirow{3}{*}{$\begin{array}{c}8.04 * * * \\
1.78,652 \\
<.001\end{array}$} & \multirow{3}{*}{.021} & {$[\mathrm{M}(\mathrm{C}, \mathrm{t} 1=\mathrm{M}(\mathrm{C}, \mathrm{t} 2)]$} & \multirow{3}{*}{$\begin{array}{l}\mathrm{M}(\mathrm{C}, \mathrm{t} 1)<\mathrm{M}(\mathrm{P}, \mathrm{t} 1) \\
\mathrm{M}(\mathrm{C}, \mathrm{t} 2)<\mathrm{M}(\mathrm{P}, \mathrm{t} 2) \\
\mathrm{M}(\mathrm{C}, \mathrm{t} 3)<\mathrm{M}(\mathrm{P}, \mathrm{t} 3)\end{array}$} \\
\hline & & & & & & & $>\mathrm{M}(\mathrm{C}, \mathrm{t} 3)$ & \\
\hline & & & & & & & $\mathrm{M}(\mathrm{P}, \mathrm{t} 2)<\mathrm{M}(\mathrm{P}, \mathrm{t} 3)$ & \\
\hline \multirow[t]{2}{*}{$\begin{array}{l}\text { Cognitive } \\
\text { Fatigue }\end{array}$} & \multirow{2}{*}{$\begin{array}{c}0.56 \\
1.84,674 \\
.574\end{array}$} & \multirow{2}{*}{.002} & \multirow{2}{*}{$\begin{array}{c}6.74 * \\
1,367 \\
.010\end{array}$} & \multirow{2}{*}{.018} & \multirow{2}{*}{$\begin{array}{c}4.81 * \\
1.84,674 \\
.021 *\end{array}$} & \multirow{2}{*}{.018} & $\mathrm{M}(\mathrm{C}, \mathrm{t} 2)>\mathrm{M}(\mathrm{C}, \mathrm{t} 3)$ & \multirow[t]{2}{*}{$\mathrm{M}(\mathrm{C}, \mathrm{t} 3)<\mathrm{M}(\mathrm{P}, \mathrm{t} 3)$} \\
\hline & & & & & & & $\mathrm{M}(\mathrm{P}, \mathrm{t} 2)<\mathrm{M}(\mathrm{P}, \mathrm{t} 3)$ & \\
\hline \multirow{2}{*}{$\begin{array}{l}\text { Interference } \\
\text { tiredness and } \\
\text { daily activities }\end{array}$} & \multirow{2}{*}{$\begin{array}{c}3.29 * \\
1.96,715 \\
.038\end{array}$} & \multirow{2}{*}{.009} & \multirow{2}{*}{$\begin{array}{c}14.25 * * * \\
1,364 \\
<.001\end{array}$} & \multirow{2}{*}{.038} & \multirow{2}{*}{$\begin{array}{c}9.07 * * * \\
1.97,715 \\
<.001\end{array}$} & \multirow{2}{*}{.024} & $\begin{array}{c}\mathrm{M}(\mathrm{C}, \mathrm{t} 2)>[\mathrm{M}(\mathrm{C}, \mathrm{t} 3)= \\
\mathrm{M}(\mathrm{C}, \mathrm{t} 1)]\end{array}$ & \multirow{2}{*}{$\begin{array}{l}\mathrm{M}(\mathrm{C}, \mathrm{t} 1)<\mathrm{M}(\mathrm{P}, \mathrm{t} 1) \\
\mathrm{M}(\mathrm{C}, \mathrm{t} 3)<\mathrm{M}(\mathrm{P}, \mathrm{t} 3)\end{array}$} \\
\hline & & & & & & & $\mathrm{M}(\mathrm{P}, \mathrm{t} 3)>\mathrm{M}(\mathrm{P}, \mathrm{t} 2)$ & \\
\hline \multirow{2}{*}{$\begin{array}{l}\text { Tiredness was not } \\
\text { understood by } \\
\text { close people }\end{array}$} & $\begin{array}{c}1.89 \\
1.97717\end{array}$ & 005 & $\begin{array}{c}0.05 \\
1363\end{array}$ & 000 & $\begin{array}{c}0.04 \\
197717\end{array}$ & 000 & - & - \\
\hline & .152 & .000 & .82 & .000 & .960 & .00 & - & \\
\hline
\end{tabular}

\footnotetext{
$*=\mathrm{p}<.05, * *=\mathrm{p}<.01, * * * \mathrm{p}<.001 ;{ }^{\dagger}$ Greenhouse-Geisser; ${ }^{\ddagger} \mathrm{C}=$ curative; $\mathrm{P}=$ Palliative; significant Helmert-Contrasts
} 